Jørgen Drud Hansen, Hassan Molana, Catia Montagna and Jørgen Ulff-Møller Nielsen

Work Hours, Social Value of Leisure and Globalisation

Department of Economics 


\title{
Work Hours, Social Value of Leisure and Globalisation
}

\author{
Jørgen Drud Hansen \\ Aarhus School of Business, Aarhus University \\ University of Southern Denmark \\ Hassan Molana \\ University of Dundee \\ Catia Montagna \\ University of Dundee \\ Aarhus School of Business, Aarhus University \\ GEP, Nottingham \\ Jørgen Ulff-Møller Nielsen \\ Aarhus School of Business, Aarhus University
}

Acknowledgements: We thank participants at the $5^{\text {th }}$ Danish International Economics Workshop and at the ETSG Conference in Rome. Montagna acknowledges the financial support of the Department of Economics, Aarhus School of Business. 


\begin{abstract}
We examine how openness interacts with the coordination of consumption-leisure decisions in determining the equilibrium working hours and wage rate when there are leisure externalities (e.g., due to social interactions). The latter are modelled by allowing a worker's marginal utility of leisure to be increasing in the leisure time taken by other workers. Coordination takes the form of internalising the leisure externality and other relevant constraints (e.g., labour demand). The extent of openness is measured by the degree of capital mobility. We find that: coordination lowers equilibrium work hours and raises the wage rate; there is a U-shaped (inverse-U-shaped) relationship between work hours (wages) and the degree of coordination; coordination is welfare improving; and, the gap between the coordinated and uncoordinated work hours (and the corresponding wage rates) is affected by the extent and nature of openness.
\end{abstract}

Keywords: coordination, corporatism, openness, capital mobility, social multiplier, welfare, work hours

JEL Classification: F2, J2, J5 


\section{Introduction}

One important stylised fact concerning the differences in the evolution of labour market outcomes (productivity, work hours, unemployment, wage rigidity) between the US and Europe is that while Americans work today about as much as in 1970, Europeans work much less. This discrepancy has generated both academic and policy debates. A key question that has arisen is whether this decline in working hours in Europe is responsible for the slowdown in its labour productivity growth. In fact, over the last thirty years productivity per man-hour in Europe grew faster than in the US, but this growth was almost completely offset by the decline in the number of hours worked per worker, suggesting that Europeans have taken a good portion of their secular increase in income in more leisure, Americans in more consumption - see Alesina et al. (2005), Blanchard (2004) and De Grauwe (2008).

How can the US-EU differences in hours worked per worker be explained? One factor that has been considered is taxation, although evidence on the importance of tax changes is ambiguous. Prescott (2004) and Rogerson (2008), among others, suggest that tax changes can account for a substantial part of the differences in hours worked between the US and continental Europe. Emphasis on the importance of taxation is also placed by Davis and Henrekson (2004). Blanchard (2004) argues that high labour taxes only explain a fraction of decline in hours worked. At the very least, the tax channel does not appear to be robust: e.g., Scandinavians have higher tax rates and work more hours than people in Continental Europe. ${ }^{1}$ Rogerson (2007) and Olovsson (2009) argue that the elasticity of hours worked with respect to taxes depends on the way governments use their tax revenue, with high taxes causing large decreases in 'market hours' in those activities which have good non-market substitutes.

Alesina et al. (2005) focus on the role of cross-country heterogeneity in labour market institutions in determining the observed differences in labour market outcomes. They point out the existence of a strong correlation between hours worked and the percentage of population covered by collective bargaining (less than $20 \%$ in the US and more than $80 \%$ in Sweden, France and Germany) and argue that lower work hours in Europe could be due to unions' influence (facilitating hours-wage trade-off), as trade unions tend to respond to negative shocks by trying to protect employment levels to the detriment of hours worked e.g., via work-sharing arrangements. As pointed out by Faggio and Nickell (2007), however,

\footnotetext{
${ }^{1}$ The explanatory role of taxation is also criticised by Nickell (2004) because of omitted variable bias, and by Alesina et al. (2005) as being at odds with the evidence on labour supply elasticity. Andersen (2009) argues that in Scandinavia the co-existence of high tax burdens and high employment levels can be explained by the employment conditionality that characterises the social safety net systems.
} 
this story does not fit the case of Sweden where working hours per working age person are relatively high - despite a generous welfare state, high taxes and strong unions. Faggio and Nickell (2007) argue that a key factor that accounts for these stylised facts is the behaviour of unions: while in France and Germany they have responded to shocks by pursuing worksharing as a means to protect employment levels, in countries such as Sweden their response has been one of coordinated wage restraints (reflecting also the internalisation of concerns about the country's international competitiveness). ${ }^{2}$ Glaeser et al. (2003) and Alesina et al. (2005) suggest that cultural differences may also be at play, contrasting the 'leisure culture' of Europeans with the 'workaholic culture' of Americans - the latter resulting from puritan Calvinist heritage. Alesina et al. (2005), however, argue that the fact that as late as the late 1960s Europeans worked longer hours than Americans (and the lack of observed correlation between a Protestant heritage and hours of work across countries) suggests that this hypothesis would imply a reversal of cultures, and state that in Europe reductions in work hours might have triggered a social multiplier effect that has led to a stronger decline in hours and resulted in higher collective leisure.

Glaeser et al. (2003) show that, in the presence of positive social interactions, strategic complementarities might arise between individual decisions which could in turn give rise to a social multiplier. Most individuals value leisure time more if it is spent together with relatives or friends. An individual's utility from leisure is thus subject to social interactions with other individuals, i.e., a positive externality exists whereby an individual's utility from leisure is higher the higher is the number of people taking leisure. Clearly, this poses a collective action problem whereby the coordination of individual decisions increases social efficiency. In the presence of a social externality, trade unions may act as coordinating agents. This gives a more nuanced view of the role of trade unions for resource allocation and welfare. Traditionally, attention has been focussed on the distortionary role of trade unions on the allocation of resources as they exploit their market power. However, when unions internalise the value of social interactions in leisure time, their overall effect on efficiency is in general ambiguous. Recently, this point has been made in several papers - see, e.g., Alesina et al. (2005). Put in this context, differences in hours worked between the US and Europe can then be at least partially explained by the degree to which this coordination problem has been overcome, and not as reflecting intrinsic differences between European and American workers regarding their respective desire for leisure. The stronger role of unions in

\footnotetext{
${ }^{2}$ Nicoletti and Scarpetta (2002) and Nickell (2004) offer evidence that the impact of taxation, unionisation and employment protection are mitigated by the degree of coordination of union activity.
} 
Europe may have contributed to turn the leisure externality into lower work hours per worker in contrast to the US, where trade unions are much weaker and do not act as their European counterparts in this respect - see Alesina et al. (2005) and De Grauwe (2008).

In this paper we explore theoretically how the nature of openness and the degree of coordination of wage/labour supply decisions (e.g., as typically reflected in the nature of labour market institutions) might interact in determining equilibrium market outcomes wages, factor utilisation, and hours worked. Specifically, we examine how the coordination of consumption-leisure decisions affects the wage rate and working hours when consumers/workers value social leisure (i.e., when a worker's marginal utility of leisure is increasing in the amount of leisure taken by other workers) and how this relationship is affected by international openness which influences the availability of factors of production and, in general, the level of economic activity.

We develop a simple static general equilibrium model of a small economy in which international openness is reflected in different degrees of capital mobility. We capture the externality from social interaction by allowing the marginal utility of leisure to depend positively on the average leisure time and examine how coordination of individual decisions interacts with openness to yield different labour market outcomes in general equilibrium. Different countries are characterised by different degrees of coordination of labour supply/wage decisions that are related to the organisational forms of industrial relations - of which the degree of centralisation of wage bargaining is just one dimension. Indeed, as it clearly emerges from the extensive literature in the area, the extent of coordination in labour markets relates to the degree of corporatism, a key aspect of which is that the unions (or, more broadly, interest-group organisations) pursue outcomes that are consistent with that of government (Pekkarinen et al, 1992). ${ }^{3}$ In this spirit, we consider different degrees of coordination where a coordinating agent (that can be thought of as a union or social planner) internalises: (i) the externality of leisure only; (ii) the externality of leisure as well as the knowledge of the partial equilibrium labour demand by firms; and (iii) the externality of leisure, firms' labour demand, as well as broader macroeconomic constraints. We refer to these respectively as basic, intermediate, and full coordination and provide a comparison between the corresponding general equilibrium solutions and the solution obtained under no coordination.

\footnotetext{
${ }^{3}$ In this context, the degree of coordination of decisions is quite distinct from that of wage bargaining centralisation and can be addressed even within a model in which unions, as wage setting agents, are not explicitly modelled.
} 
Our results suggest that, in general, (with and without coordination) a stronger leisure externality results in a lower labour supply and in a higher wage and that this effect is stronger when the leisure externality is internalised by coordination of individuals' labour supply decisions. We show that coordination reduces equilibrium working hours and raises the corresponding wage rate. However, we find a U-shaped relationship between hours worked and the degree of coordination of labour supply decisions (and an inverse-U-shaped relationship between wages and the degree of coordination of labour supply decisions). This is consistent with the evidence on the higher work hours per working age person in Scandinavian economies relative to less coordinated industrial relations systems in other Continental European countries. We also find that the gap between the coordinated and uncoordinated equilibrium labour supply (and the corresponding wage rates) is affected by the extent of globalisation. In particular, for countries that are net importers of capital (and have a positive trade balance) raising the degree of openness increases both the labour supply and the wage rate - although with intermediate levels of coordination labour supply may also reduce. Again, this is consistent with the fact that - as also pointed out by Faggio and Nickell (2007) - the Swedish social pact, based on the internalisation of concerns about the country's international competitiveness, has resulted in wage moderation. Finally, we find that coordination is welfare improving and that stronger leisure externalities enhance this improvement.

The rest of the paper is organised as follows. Section 2 sets out the model. Section 3 derives and compares the general equilibrium solutions under different degrees of coordination of the wage-employment decisions. Section 4 concludes the paper.

\section{The model}

We model a small open economy producing a freely traded homogeneous final good under a constant returns to scale technology with capital and labour (man-hours). The labour force and capital endowment are given exogenously. Labour is assumed to be internationally immobile and the extent of globalisation is determined by the degree of capital mobility ${ }^{4}$. Workers/consumers are identical and each is endowed with a fixed amount of capital and

\footnotetext{
4 The international mobility of labour is insignificant relative to that of capital, and is ruled out here by assumption to simplify the analysis; allowing for labour mobility requires an infinitely elastic labour supply at the world wage rate which introduces some 'indeterminacy' problems that complicates the analysis. It is also plausible to conjecture that the social interaction effect may be weakened by labour mobility, to the extent that it might increase the cultural heterogeneity of workers.
} 
man-hours. The former is supplied to the capital market and the latter is optimally divided between work and leisure hours; the representative consumer maximises a utility function in consumption and leisure which captures the externality of leisure across consumers.

\subsection{Production and factor demands}

Denoting aggregate quantities of output, capital and man-hours by $Y, K$ and $H$ respectively, the production function is $Y=A K^{\lambda} H^{1-\lambda}$, where $A$ is a scaling constant and $0<\lambda<1$. Given that all markets are perfectly competitive, factor demand equations are $w=(1-\lambda) A\left(K^{d}\right)^{\lambda}\left(H^{d}\right)^{-\lambda}$ and $r=\lambda A\left(K^{d}\right)^{\lambda-1}\left(H^{d}\right)^{1-\lambda}$, where the superscript $d$ denotes demand and $w$ and $r$ are respectively the price of labour and capital relative to the price of $Y$ $(P)$ - i.e., they are real wage and rent, respectively; since there is no money in the model, output is used as numeraire and $P$ is normalised to unity.

Given that the labour force $\bar{L}$ is fully employed, we write the above equations in per capita terms as:

$$
\begin{aligned}
& y=A k^{\lambda} h^{1-\lambda}, \\
& w=(1-\lambda) A\left(k^{d}\right)^{\lambda}\left(h^{d}\right)^{-\lambda}, \\
& r=\lambda A\left(k^{d}\right)^{\lambda-1}\left(h^{d}\right)^{1-\lambda},
\end{aligned}
$$

where $y=Y / \bar{L}, h^{d}=H^{d} / \bar{L}$ and $k^{d}=K^{d} / \bar{L}$. By virtue of the constant returns to scale technology and perfect competition, the zero profit condition $y=w h+r k$ holds and a one-toone correspondence between $w$ and $r$,

$$
r=\lambda(1-\lambda)^{(1-\lambda) / \lambda} A^{1 / \lambda} w^{-(1-\lambda) / \lambda},
$$

is obtainable from (1)-(3).

\subsection{Consumption and labour supply}

The representative worker's/consumer's preferences are described by a utility function which captures the benefits from social interaction. In the presence of social interactions in leisure, the marginal utility from leisure of an individual depends positively on the average amount of leisure of the individual's peers. Thus, there are strategic complementarities between individual actions (see for example Scheinkman, 2008) that, in this context, result in a social multiplier in the worker's labour supply/leisure decision. In general, we may postulate a 
separable utility function in consumption and leisure ${ }^{5}, u=v(c)+\ell(e, \tilde{e}, \beta)$, where $c$ is consumption, $e$ is leisure hours, $\tilde{e}$ is the reference group's average leisure time and $\beta$ is a parameter that measures the importance of social interaction in the preferences. We need $v$ to be concave in $c, \ell$ to be concave in $e$ and $\ell_{e}^{\prime}$ to be increasing in $\tilde{e}$. We also require the resulting labour supply function for the representative worker, $h=h(w)$ say, to satisfy $h^{\prime}(w)>0$ and $h^{\prime}(w)$ to be decreasing in $\beta$. Specifically, to obtain closed form solutions, we assume

$$
u=\gamma \ln c+(\mu \tilde{e})^{\beta-\alpha} e^{\alpha}, \quad \gamma>0, \mu>0, \quad 0<\alpha<\beta<1,
$$

which can be shown to satisfy the required properties as long as the scale parameter $\mu$ satisfies $\mu>1 / \tilde{e}{ }^{6} \mathrm{We}$ normalise a worker's total endowment of hours to unity and assume that $\tilde{e}$ is the perceived average leisure across all workers. Thus, denoting the representative worker's supply of work hours by $h^{s}$, the hours restriction is

$$
e+h^{s}=1 \text {. }
$$

The internalisation of the leisure externalities in the time allocation decisions of individuals intrinsically rests on the coordination of individual actions. This coordination can be thought of as resulting from the action of a collective agent - for example, a social planner or a trade union. The nature and extent of coordination typically depends on institutional factors such as the nature of industrial relations and/or government policies. Given the simple setup used here we shall not model explicitly the coordinating agent, but consider nonetheless different cases corresponding to varying degrees of coordination of labour supply decisions which can be thought of as reflecting the different degrees of corporatism characterising the organisational forms of industrial relations of different countries.

\subsection{Openness}

In order to assess the impact of 'globalisation', we invoke the small open economy assumption with free trade in the final good and some degree of capital mobility. The latter is assumed to be governed by

\footnotetext{
${ }^{5}$ For similar specifications in the literature, see for instance, Alesina et al. (2005) and Groedner and Knieser (2006).

${ }^{6}$ The social interaction effect of leisure operates through $\tilde{e}$ and $(\beta-\alpha)$ determines the extent to which the marginal utility from leisure of an individual depends on the average leisure time enjoyed by others. Since $\alpha$ is kept constant throughout the analysis we refer to $\beta$ as the relevant parameter. While in some circumstances $\beta \geq 1$ may be plausible, it is not considered here so as to rule out any unfeasible behaviour.
} 


$$
\frac{k}{\bar{k}}=1+\delta\left(\frac{r}{r^{*}}-1\right), \quad \delta \geq 0,
$$

which for convenience is written in per capita terms, where $\bar{k}$ is a worker's/consumer's endowment of capital, with $k=K / \bar{L}$ and $\bar{k}=\bar{K} / \bar{L}$. This equation is commonly used in the literature and is consistent with the conventional portfolio approach in which the capital flow $(k-\bar{k})$ is determined by the interest rate differential $\left(r-r^{*}\right)$, where $r^{*}$ is the return to capital (the interest rate) in the rest of the world. $\delta$ captures the degree of capital mobility: when $\delta=0$ capital is internationally immobile, $k=\bar{k}$ and the supply of capital is restricted to the country's endowment; $\delta>0$ corresponds to partial capital mobility where capital flows are directly determined by the interest rate differential rate; perfect capital mobility is achieved as $\delta \rightarrow \infty$, where $r=r^{*}$ holds and there may be capital in- or out-flow. In this setup, therefore, $\delta$ can be thought as a measure of globalisation.

Since free trade in goods equalises the domestic and foreign price of output, we can continue to disregard the price level (keeping $P=1$ ). The following equations show, in per capita terms, the balance of payments condition under capital inflow and outflow (with partial capital mobility) and perfect capital mobility, respectively

$$
\begin{aligned}
& y-c=-r(\bar{k}-k)>0 ; \quad r>r^{*} \text { and } \bar{k}<k, \\
& y-c=-r^{*}(\bar{k}-k)<0 ; \quad r<r^{*} \text { and } \bar{k}>k, \\
& y-c=-r^{*}(\bar{k}-k) ; \quad r=r^{*} \text { and either } \bar{k} \geq k \text { or } \bar{k}<k .
\end{aligned}
$$

The representative consumer's budget constraint corresponding to the three cases of capital mobility are

$$
\begin{aligned}
& c=w h^{s}+r \bar{k} ; \quad r>r^{*} \text { and } \bar{k}<k, \\
& c=w h^{s}+r k+r^{*}(\bar{k}-k) ; \quad r<r^{*} \text { and } \bar{k}>k, \\
& c=w h^{s}+r^{*} \bar{k} ; \quad r=r^{*} \text { and either } \bar{k} \geq k \text { or } \bar{k}<k .
\end{aligned}
$$

It is worth noting that (9.i) can be obtained from the corresponding (8.i) and the zero profit condition, $y=w h+r k$. 


\section{General equilibrium solutions}

Given our purpose, we focus on obtaining the general equilibrium solution for $(h, w)$ and examine how it is affected by the extent of globalisation and the strength of the leisure externality, captured by parameters $\delta$ and $\beta$ respectively. To do so, we reduce the model to two equations in $(h, w)$ by substituting for all other variables in the demand and supply equations for work hours. We then use these to examine the resulting labour market equilibrium and compare equilibria across different scenarios, i.e., no coordination and basic, intermediate and full coordination.

\subsection{Demand for work hours}

For any given $k^{d}$, the partial equilibrium demand for labour is given by (2). From (2), using (4) and (7) and imposing the capital market equilibrium condition $k^{d}=k$, we obtain

$$
h=\bar{k}\left(1+\delta\left(\frac{\lambda(1-\lambda)^{(1-\lambda) / \lambda} A^{1 / \lambda} w^{-(1-\lambda) / \lambda}}{r^{*}}-1\right)\right)\left(\frac{(1-\lambda) A}{w}\right)^{1 / \lambda} .
$$

Equation (10) is the locus of all combinations of $h$ and $w$ which satisfy demand for work hours in general equilibrium. For given values of $r^{*}, \bar{k}, \lambda$ and $A$ (which are kept constant throughout the paper), the shape and position of this locus in the $(h, w)$ space are determined by the extent of capital mobility captured by $\delta$. Figure 1 illustrates this (all figures are presented in Appendix 1). As expected, the locus is downward sloping and convex, reflecting the existence of a trade-off between $h$ and $w$. More specifically, a rise in $\delta$ rotates the locus anticlockwise at $w=\hat{w}$, the value of $w$ that satisfies (4) for $r=r^{*}$ and corresponds to the perfect capital mobility locus. Thus, $w<\hat{w}(w>\hat{w})$ corresponds to $r>r^{*}\left(r<r^{*}\right)$ where there is capital inflow (outflow); at higher (lower) values of $h$, i.e. $h>\hat{h}(h<\hat{h})$, there is capital inflow (outflow) since firms are willing to pay a relatively lower (higher) $w$ and hence $r>r^{*}\left(r<r^{*}\right)$. To see the impact of $\delta$, suppose that $\delta$ is small (the solid curve) and consider a point such as B where there is capital inflow, thus $r>r^{*}, h>\hat{h}$ and $w<\hat{w}$. A rise in $\delta$ increases the inflow of capital for the given $\left(r-r^{*}\right)$. This raises the marginal product of labour and increases the demand for labour. As a result, a rise in $\delta$ rotates the locus such that it lies above (below) the original one when there is capital inflow (outflow). 


\subsection{Supply of work hours and the general equilibrium solution}

We derive the supply of work hours under a number of alternative scenarios: (i) the absence of coordination among workers, with each individual finding her own optimal consumption and leisure taking $\tilde{e}$ as given; (ii) a 'basic' level of coordination of consumption-leisure decisions across workers by a coordinating agent - e.g., a trade union - that internalises the leisure externality by setting $\tilde{e}=e$; (iii) an 'intermediate' level of coordination that internalises the leisure externality as well as the knowledge of the partial equilibrium labour demand facing firms (in an industrial relations context, this could be thought of as a firmlevel wage setting union case); and (iv) a 'full' level of coordination that internalises the leisure externality, firms' labour demand as well as broader macroeconomic constraints in general (this can be thought as the corporative 'all-encompassing' coordination case). These four different equilibrium regimes (henceforth respectively labelled with a subscript $U, B, I$ and $F$ ) are derived in the following subsections under capital inflow and outflow respectively.

\subsubsection{Supply of work hours with capital inflow}

\subsubsection{No coordination}

On the assumption that each consumer/worker takes $w$ and $r$ as given, the first order condition for maximising the utility function in (5) subject to the hours and budget constraints in (6) and (9.1), is

$$
\frac{\gamma w}{w h+r \bar{k}}-\alpha(\mu \tilde{e})^{\beta-\alpha}(1-h)^{\alpha-1}=0,{ }^{7}
$$

from which the corresponding supply function in general equilibrium,

$$
\frac{\gamma}{h+\bar{k} \lambda(1-\lambda)^{(1-\lambda) / \lambda} A^{1 / \lambda} w^{-1 / \lambda}}-\alpha \mu^{\beta-\alpha}(1-h)^{\beta-1}=0,
$$

is obtained if we set $\tilde{e}=e=(1-h)$ and replace $r$ using equation (4). This equation gives the locus of all combinations of $h$ and $w$ that satisfy the uncoordinated labour supply equation in general equilibrium with capital inflow. Figure 2 illustrates (11.1) and (10) in the $(h, w)$ space. Whilst the labour supply locus is independent of the extent of capital mobility - as $\delta$ does not appear in (11.1) - the externality parameter $\beta$ affects its position. In particular, ceteris

\footnotetext{
${ }^{7}$ For a given $r$, this equation yields the individual worker's supply of work hours, $h=h(w)$ which satisfies $h^{\prime}(w)>0$ and $h^{\prime}(w)$ is decreasing in $\beta$.
} 
paribus, a higher $\beta$, and hence a larger leisure externality, shifts the locus inwards to the left, as illustrated in Figure 2. This result is consistent with the existence of a social multiplier and can be explained by recalling that points on the supply locus correspond to the maximum utility. For any given point on the locus, $\left(h_{0}, w_{0}\right)$ say, consider increasing $\beta$. The first term on the left-hand-side of (11.1) is unaffected whereas the second term rises. Thus, with a higher $\beta,\left(h_{0}, w_{0}\right)$ is no longer optimum since it does not satisfy $(11.1) ; w$ ought to rise above $w_{0}$ so as to equalise the two terms in (11.1) and to restore the optimality of $h_{0}$. Put differently, the second term captures the marginal utility of leisure which rises with $\beta$ and induces the individual to work less for a given wage rate.

Figure 2 illustrates how the uncoordinated general equilibrium is affected by changes in $\delta$ and $\beta$. For a given $\beta$, increasing globalization (i.e. a higher capital mobility and hence $\delta$ ) increases the inflow of capital, raising the marginal productivity of and demand for labour. This is followed by a rise in both working hours and the wage rate, as illustrated by the movement from $E_{U 1}$ to $E_{U 2}$ or alternatively the movement from $E_{U 1}^{\prime}$ to $E_{U 2}^{\prime}$ in case of a larger $\beta$. If - for a given degree of capital mobility and an initial capital stock - the social interaction preference parameter $\beta$ increases, labour supply reduces resulting in a higher wage and in a lower working hours, as shown by the movement from $E_{U 1}$ to $E_{U 1}^{\prime}$ or from $E_{U 2}$ to $E_{U 2}^{\prime}$. In summary, when labour supply is not coordinated, (i) comparing two economies with the same preference for social interaction, the one which is more open will have relatively higher wage and work hours; and (ii) comparing two economies with the same degree of openness, the one with a stronger preference for social interaction will have a higher wage and lower work hours.

\subsubsection{Basic coordination}

The 'basic' level of coordination across individuals in deciding optimal wage-hours combinations involves internalising the leisure externality without taking into account firms' behaviour and/or broader 'macroeconomic' factors. ${ }^{8}$ Hence, the utility function of the representative worker-consumer is obtained by combining equations (5) and (6) and letting $\tilde{e}=e=(1-h)$ which is maximised subject to the budget constraint in (9.1). Eliminating $c$

\footnotetext{
${ }^{8}$ This scenario is considered as a benchmark and would fall somewhat short of the actions of a coordinating agent (such as a union) which, even at the lower level of coordination - the firm-level - would plausibly internalised the firm's labour demand, as shall be seen in the next subsection.
} 
from the utility function using (9.1) yields $u=\gamma \ln (w h+r \bar{k})+\mu^{\beta-\alpha}(1-h)^{\beta}$. The first order condition for choosing $h$ to maximise $u$ keeping $w$ and $r$ as given is

$$
\frac{\gamma w}{w h+r \bar{k}}-\beta \mu^{\beta-\alpha}(1-h)^{\beta-1}=0
$$

from which the corresponding supply function in general equilibrium,

$$
\frac{\gamma}{h+\bar{k} \lambda(1-\lambda)^{(1-\lambda) / \lambda} A^{1 / \lambda} w^{-1 / \lambda}}-\beta \mu^{\beta-\alpha}(1-h)^{\beta-1}=0
$$

is obtained by replacing $r$ using (4). This equation is the locus of all $h$ and $w$ combinations that satisfy the coordinated labour supply equation in general equilibrium with capital inflow. This locus too is independent of $\delta$ (the extent of capital mobility) and comparing (12.1) with (11.1) shows that, relative to the uncoordinated case, coordination leads to a reduction in the supply of work hours at any given wage rate. This occurs because the internalisation of the leisure externality directly implies that the opportunity cost of work is now higher - which is evident by comparing the second terms on the left-hand-sides of (11.1) and (12.1). As a result, the graph of (12.1) in the $(h, w)$ space lies above and to the left of that of (11.1). Consistent with the case with no coordination, and for the same reasons, an increase in $\beta$ shifts the supply locus to the left, except that the shift is now larger.

Figure 3 illustrates the general equilibrium with basic coordination, and compares it to the uncoordinated case. For a relatively small value of $\beta$ and a given $\delta$, the effect of coordination results in a move from $E_{U 1}$ to $E_{B 1}$ (with low openness, i.e. small $\delta$ ) or from $E_{U 2}$ to $E_{B 2}$ (with high openness, i.e. large $\delta$ ). Hence, introducing a basic level of coordination will result in relatively higher wages and lower work hours, and the impact on the latter is stronger the more open is the economy. As discussed above, coordination increases the opportunity cost of work and shifts the labour supply curve inwards. A higher degree of capital mobility will increase capital inflow and, by increasing the marginal product of labour, will result in a higher wage and in lower work hours. The fall in hours, given the leisure externality, will be higher under coordination than under no-coordination. For a given $\beta$, the effect of increasing openness is qualitatively identical to the uncoordinated case. For a given $\delta$, an increase in the social preference parameter $\beta$ raises wages and lowers work hours. This is seen as moving from $E_{B 1}$ to $E_{B 1}^{\prime}$ (with low openness, small $\delta$ ) or from $E_{B 2}$ to $E_{B 2}^{\prime}$ (with high openness, large $\delta$ ). Whilst qualitatively this result is the same as that obtained 
under no coordination, quantitatively the same change in $\beta$ generates a bigger impact when labour supply decisions are coordinated as seen by the movement from $E_{U 1}$ to $E_{U 1}^{\prime}$ or $E_{U 2}$ to $E_{U 2}^{\prime}$, respectively. This result reflects the social multiplier effect triggered by the internalization of the leisure externality under coordination, with a higher $\beta$ capturing a higher degree of complementarity between individuals' leisure choice.

In summary, comparing two economies with the same preference for social leisure and degree of openness (given $\delta$ and $\beta$ ), the one in which workers' consumption-leisure decisions are coordinated will have higher wages and lower work hours. Also, starting with a low level of openness and a weak leisure externality (small $\delta$ and $\beta$ ): (i) raising the extent of openness (increasing $\delta$ ) will increase both $w$ and $h$ in both economies; (ii) strengthening the leisure externality (increasing $\beta$ ) increases wage and reduces work hours in both economies 9 .

\subsubsection{Intermediate coordination}

If the coordination of workers' consumption-leisure decisions is performed by a collective agent such as a union, it is plausible to postulate that the agent internalises available information concerning firms and the broader aspects of the economy that might impact on workers' employment and income. The extent to which the available information is taken into account can be thought of as reflecting the degree of coordination characterising the country's industrial relations system, with higher levels of coordination embodying a higher degree of encompassment of broader (macro) economic constraints. In this subsection, we shall assume that the coordinating agent internalises the information that firms pay workers their marginal product - i.e., equation (2) - but disregards how $r$ and $k$ are determined and thus takes these as given. If we thought of this agent as a union, then this case would correspond to firm-level unions. In this intermediate coordination case, the utility of the representative worker-consumer is identical to that used in the basic coordination case - i.e., $u=\gamma \ln (w h+r \bar{k})+\mu^{\beta-\alpha}(1-h)^{\beta}-$ which is now maximised subject to the demand for work hours in (2), keeping $r$ and $k$ as given constants. ${ }^{10}$ The first order condition is

\footnotetext{
${ }^{9}$ Figure 2 shows the typical case in which a rise in $\delta$ increases $h$ more in the uncoordinated economy whilst a rise in $\beta$ increases $w$ more in the coordinated economy.

${ }^{10}$ Clearly, for any given $r$ and $k$, choosing $h$ in this context where the coordinator internalises the partial equilibrium demand by the firm amounts to choosing $w$. Put differently, the objective function can be written in terms of either $h$ or $w$ when internalising the labour demand function - it is in this sense that this case can be thought of as corresponding to the wage setting firm-level monopoly union.
} 


$$
\frac{\gamma(1-\lambda)^{2} A k^{\lambda} h^{-\lambda}}{(1-\lambda) A k^{\lambda} h^{1-\lambda}+r \bar{k}}-\beta \mu^{\beta-\alpha}(1-h)^{\beta-1}=0,
$$

which together with the remaining two equations in $h, k$ and $r$, i.e. (3) and (7), can be solved to determine their corresponding general equilibrium values in terms of $\gamma, \beta, \lambda, \delta, A, r^{*}$ and $\bar{k}$. The solution for $w$ is then obtained using (2). The algebraic expressions for these solutions are rather cumbersome and analytically unwieldy but it can be shown that, with this type of coordination, the optimal values of $h$ is below (and the optimal value of $w$ is above) that obtained in the previous cases. ${ }^{11}$ This is shown in Figure 4 (drawn for given $\delta$ ) by point $E_{I}$ and comparison with the equilibrium solutions under basic coordination and no coordination, $E_{B}$ and $E_{U}$ respectively, shows that $h_{I}<h_{B}<h_{U}$ and $w_{I}>w_{B}>w_{U}$. Hence, by taking into account the trade-off between $w$ and $h$ on the demand curve, intermediate coordination leads to a further reduction in work hours and to a rise in the wage. The reason why in this case hours are lower than in the basic coordination case is that the coordinating agent internalises the (partial equilibrium) trade-off between employment and wage, whereby a lower employment (which reduces income and hence consumption) will be compensated by a higher wage. Analytically, as shown in more detail in Appendix 2, while the marginal utility of leisure is unaffected by coordination - i.e., the second term of left-hand-sides of (12.1) and (13.1) are identical - the marginal utility of consumption is lower under intermediate coordination, as can be seen by comparing the first term of the left-hand-sides of (12.1) and (13.1). Hence, $h$ has to be lower to balance the marginal utilities of consumption and leisure for (12.1) and (13.1) to hold. Figure 4 also shows the effects of a change in $\beta$; as expected, the higher is $\beta$ the lower will be the optimal work hours (and the lower will be the wage rate), resulting in a bigger gap between the coordinated and uncoordinated solutions for $w$ and $h$.

With respect to the role of international openness, the larger is $\delta$ the higher is the optimal $h$ and hence the higher is the corresponding $w$, as illustrated in Figure 5 (drawn for given $\beta$ ). Consider the initial equilibrium at $E_{I 1}$ and let $\delta$ rise from $\delta_{1}$ to $\delta_{2}$. Ceteris paribus, we move from $E_{I 1}$ to $E_{I 1}^{\prime}$, but the increase in $h$ reduces the utility - as $w$ is kept constant and $h$ is increased; see (13.1). Thus, at $E_{I 1}^{\prime}$ it is desirable for the worker if we reduce $h$ and increase $w$ along the new demand curve associated with a higher $\delta=\delta_{2}$. The new optimal

\footnotetext{
${ }^{11}$ We do not present the algebraic expressions here (they are available on request) but show the general analytical proofs in Appendix 2.
} 
point is shown by $E_{I 2}$, where we have assumed that the rise in openness has increased both $w$ and $h$, relative to their starting values at $E_{I 1} \cdot{ }^{12}$

\subsubsection{Full coordination}

In this subsection the coordinating agent is assumed to have full knowledge of the economy and to utilise it when maximising the utility of the representative worker-consumer. This case corresponds to full coordination of the consumption-leisure decision and can be thought of as the 'all-encompassing' corporatist case. The utility function is as in the previous cases with coordination - i.e., $u=\gamma \ln (w h+r \bar{k})+\mu^{\beta-\alpha}(1-h)^{\beta}-$ but the internalisation of the macroeconomic constraints now involves maximising $u$ subject to equations (1), (2), (3), (7) and (9.1). In general, these equations together with the first order condition for maximisation form a system of six equations which determine the general equilibrium solution for the six unknowns, $y, k, r, w, h$, and $c$. Specifically, the full coordination entails first using equations (1), (2), (3), (7) and (9.1) to find the solutions for $y, k, r, w$ and $c$ in terms of $h$, and then maximising $u$ subject to these solutions. This yields the optimal, fully coordinated, values of $h$ and $w$ which, for the same values of the parameters and exogenous variables, can be shown to lie between the corresponding values obtained under the basic and the intermediate coordination cases, i.e., $h_{I}<h_{F}<h_{B}$ and $w_{B}<w_{F}<w_{I}$ hold (see Appendix 2) as illustrated in Figure 6.

The intuition behind the larger working hours and lower wage under full coordination relative to the intermediate coordination case is that the coordinator now takes into account the effect of work hours (and the associated wage level) on the interest rate and the ensuing capital inflow, and therefore the total size of the capital stock. Recall that, given the trade-off between wage and interest rate in (4), a higher wage results in a smaller interest rate and in a lower capital inflow which, ceteris paribus, reduces the marginal productivity of labour and lowers output. It is taking account of this mechanism, and hence mitigating the negative effect of a higher wage on employment and income that leads the coordinator in this case to set higher hours (and a lower wage) relative to the intermediate case.

Thus, what emerges here is an inverse U-shaped relationship between wage levels and the degree of coordination of labour supply decisions (to which corresponds a U-shaped relationship between work-hours and degree of coordination). This result offers a rationale for the evidence of the high work hours (per working age person) in Scandinavian economies

\footnotetext{
${ }^{12}$ It should be stressed that whilst $w_{I 2}>w_{I 1}$ always holds, $h_{I 2}<h_{I 1}$ is also a feasible outcome in this case.
} 
relative to those characterising less coordinated industrial relations systems in other continental European countries. ${ }^{13}$ Specifically, despite its stylised nature this model captures the fact that a key factor in explaining the different pattern of work in Scandinavian countries (relative to other European economies such as France and Germany) is that in these small open Nordic countries the (corporatist) social pact between the trade unions and the government, resulting in wage moderation, has rested on the internalisation of the implications of the wage and labour supply decisions on the country's international competitiveness $^{14}$ - see, for example, Faggio and Nickell (2007) for a detailed discussion of this issue. Finally, it can be shown that with full coordination the impact of a change in the extent of openness and importance of social interaction - measured by $\delta$ and $\beta$, respectively is qualitatively identical to that obtained with intermediate coordination and can be illustrated using Figures 4 and 5 above. Figure 7 illustrates these points: it depicts the U-shaped relationship between work-hours and degree coordination of labour supply decisions and it also shows how this relationship shifts with a rise $\delta$ and $\beta$. In order to confront the shape of this theoretical relationship with the data, in Figure 8 we plot the fitted values from a (quadratic smoothing) regression of work hours on an index of centralisation of wage bargaining using pooled data from 18 OECD countries for the period 1970-2000. ${ }^{15}$ The graph clearly shows, consistent with our theoretical result, that there is a U-shaped relationship between hours worked and centralisation in the wage determination process.

\subsubsection{Supply of work hours with capital outflow}

We now briefly examine, for completeness, the equilibrium under capital outflow. With capital outflow, the demand for work hours remains the same and can be represented by Figure 1 except that the market equilibrium now occurs at wages above $\hat{w}$ since now $r<r^{*}$. Also, note that the relevant budget constraint used in this case is given by equation (9.2).

\footnotetext{
${ }^{13}$ This result is also consistent with findings in the literature of a hump-shaped relationship between degree of bargaining coordination and the distortionary effects of unionisation, e.g. Calmfors and Driffill (1988) and Freeman (1988), who focus on employment, and Summers et al. (1993) and Alesina and Perotti (1997), who examine the role of taxation and fiscal policy.

${ }^{14}$ The policy of wage restrains that has accompanied the lifting of controls on foreign direct investment and has resulted in a higher competitiveness is often referred to as a key factor explaining the rebound in Sweden's current account deficit in the 1990s.

15 This index of bargaining centralization is the interpolated version of that provided in Table 3.5 of OECD (2004). It is within the range [1,5] and increasing in the degree of centralization. The countries are Australia, Belgium, Canada, Denmark, Finland, France, Germany, Ireland, Italy, Japan, Netherlands, New Zealand, Norway, Portugal, Spain, Sweden, United Kingdom and United States. We have taken the series from Nickell (2006) which provides a comprehensive description of the series used in different studies.
} 


\subsubsection{No coordination}

Following the same procedure as in the capital inflow case, the first order condition for utility maximisation is

$$
\frac{\gamma w}{w h+r^{*} \bar{k}(1-x)(1-\delta(1-x))}-\alpha \mu^{\beta-\alpha}(1-h)^{\beta-1}=0
$$

where $x=\frac{\lambda(1-\lambda)^{(1-\lambda) / \lambda} A^{1 / \lambda} w^{-(1-\lambda) / \lambda}}{r^{*}} \cdot{ }^{16}$ (11.2) is the general equilibrium locus of combinations of $h$ and $w$ on the uncoordinated supply. Unlike its counterpart under capital inflow, i.e. (11.1), it depends on the extent of openness through $\delta$ and becomes steeper the larger is $\delta$ within the relevant range where $w>\hat{w} .{ }^{17}$ Also, since a rise in $\beta$ shifts the supply locus to the left, in this case too a higher leisure externality leads to a reduction in work-hours supplied at the same wage. Thus: (i) for any given $\beta$, the more open is the economy, the lower are the equilibrium values of $w$ and $h$; (ii) for any given $\delta$, the stronger is the leisure externality the lower is the equilibrium $h$ and the higher is the corresponding $w$.

\subsubsection{Impact of coordination}

With internalisation of the leisure externality and taking account of equations (5), (6) and (9.2) the objective function is

$$
u=\gamma \ln \left(w h+r k+\left(r^{*}-r\right) \bar{k}\right)+\mu^{\beta-\alpha}(1-h)^{\beta},
$$

which will be the same in all coordination cases.

With basic coordination, the first order condition for maximising (14) yields the following general equilibrium supply locus of combinations of $h$ and $w$

$$
\frac{\gamma w}{w h+r^{*} \bar{k}(1-x)(1-\delta(1-x))}-\beta \mu^{\beta-\alpha}(1-h)^{\beta-1}=0
$$

Again, unlike its counterpart under capital inflow - i.e., (12.1) - this locus depends on the extent of openness and its graph is similar to (11.2) in the $(h, w)$ space except that, for all

\footnotetext{
${ }^{16}$ Note that $x<1$ as long as $r<r^{*}$.

${ }^{17}$ It is straightforward to verify that the loci corresponding different values of $\delta$ are tangent at $w=\hat{w}$ corresponding to $r=r^{*}$, but become steeper (flatter) the larger is $\delta$ as $w>\hat{w}(w<\hat{w})$. Also, for very large values of $\delta$ the locus bends backwards at some high value of $w>\hat{w}$ but this occurs above the intersection with demand for the same $\delta$ and does not lead to multiple equilibria.
} 
given parameter values, it lies to its left; however, as in the capital inflow case, a rise in $\beta$ shifts the curve to the left. Thus, as in the capital inflow case: (i) compared with the nocoordination case, for any given $\delta$ and $\beta$, basic coordination reduces the equilibrium value of $h$ and raises the corresponding value of $w$; as in the no-coordination case, (ii) for any given $\beta$, the more open is the economy the lower are the equilibrium values of $w$ and $h$; and (iii) for any given $\delta$, the stronger is the social interaction externality the lower is the equilibrium value of $h$ and the higher is the corresponding value of $w$.

Moving to intermediate coordination, the objective function in (14) is maximised subject to the demand for work hours in (2) taking as given $r$ and $k$. The first order condition is

$$
\frac{\gamma(1-\lambda)^{2} A k^{\lambda} h^{-\lambda}}{(1-\lambda) A k^{\lambda} h^{1-\lambda}+r k+r^{*}(\bar{k}-k)}-\beta \mu^{\beta-\alpha}(1-h)^{\beta-1}=0,
$$

which together with (2), (3) and (7) can be solved to determine the general equilibrium values of $w, h, k$ and $r$. Again, we find $h_{I}<h_{B}<h_{U}$ and $w_{I}>w_{B}>w_{U}$ which are qualitatively identical to the results obtained with capital inflow. In addition, in common with the uncoordinated and basic cases, we find that (i) for any given $\delta$, the stronger are social interactions the lower is the equilibrium value of $h$ and the higher is the corresponding value of $w$; and (ii) for any given $\beta$, the more open is the economy the lower are the equilibrium values of $w$ and $h$.

Finally, with full coordination, (14) is maximised subject to the solution of (1), (2), (3) and (7) for $y, k, r$ and $w$ in terms of $h$. We find the same qualitative results obtained under capital inflow, namely $h_{I}<h_{F}<h_{B}\left\langle h_{U}\right.$ and $w_{I}>w_{F}>w_{B}>w_{U}$ to hold, supporting the existence of an inverse U-shaped relationship between wages (and a U-shaped relationship between work hours) and degree of coordination. Also, as in the intermediate coordination case, we find that (i) for any given $\delta$, the higher is $\beta$ the lower is the equilibrium value of $h$ and the higher is the corresponding value of $w$; and (ii) for any given $\beta$, the higher is $\delta$ the lower are the equilibrium values of both $w$ and $h$.

\subsection{Welfare effects of coordination}

In this section we examine the welfare effects of coordination in the labour supply-wage decision of workers. We do this by comparing the values of the maximised utilities corresponding to different cases, denoted with $V$. It is straightforward to show that coordination increases welfare in that, under both capital inflow and outflow, the higher is the 
degree of coordination the larger is $V$ - i.e., for any given $\beta$ and $\delta, V_{F}>V_{I}>V_{B}>V_{U}$ always holds. Also, for any given $\delta$, in all cases $V$ is always increasing in $\beta$, as expected. Finally, with respect to the role of openness, we find that, for any given $\beta$, the higher is $\delta$ the larger is $V$ when there is capital inflow. But with capital outflow, this result does not always hold since in this case a rise in $\delta$ lowers both $h$ and $w$ and $V$ falls if the net effect of the fall in wage income dominates in the indirect utility function. ${ }^{18}$

\section{Conclusions}

This paper has examined how openness interacts with the coordination of consumptionleisure decisions in determining the equilibrium working hours and wage rate when there are leisure externalities stemming from social interactions.

Coordination takes the form of internalising the leisure externality and other relevant constraints and leads to a lower equilibrium working hours and a higher wage rate. However, the impact of coordination on hours and wage is not monotonic, as we find a U-shaped relationship between hours worked and the degree of coordination of the labour supply decisions (to which corresponds and inverse-U-shaped relationship between wages and degree of coordination). We also find that the gap between the equilibrium coordinated and uncoordinated labour supply (and the corresponding wage rates) is affected by the extent of globalisation. In particular, for countries that are net importers of capital (and have a positive trade balance) raising the degree of openness increases both the labour supply and the wage rate - although with intermediate levels of coordination labour supply may also reduce. Finally, we find that coordination is welfare improving and that the existence of leisure externality enhances this improvement.

The key results of the paper, on the whole, are in line with the empirical observation that, relative to other European countries, the Scandinavian countries - characterised by more coordinated systems of industrial relations - have higher work hours per working age person. More generally, as we showed, preliminary evidence suggests the existence of a U-shaped relationship between hours worked and degree of centralisation of the wage setting process in OECD countries. Further explorations in this direction would go beyond the aims of this paper. Our results suggest, however, that further research is required - both at the empirical

\footnotetext{
${ }^{18}$ Our calculations show that the fall in $V$ due to the rise in openness emerges with intermediate coordination, as in this case $w h$ falls substantially relative to the other coordination cases.
} 
and theoretical level - to highlight the interaction between labour market institutions, openness, and working time patterns. 


\section{References}

Alesina, A., E. Glaeser, and Sacerdote, B. (2005), "Work and Leisure in the US and Europe: Why So Different?", NBER Working Paper No. 9263, National Bureau of Economic Research.

Alesina, A. and Perotti, R. (1997), "The Welfare State and Competitiveness", American Economic Review, 87(5), 921-939.

Andersen, T.M. (2009), “Taxes and Employment - Is there a Scandinavian Puzzle?", Economic Papers 359, Economic and Financial Affairs, European Commission.

Blanchard, O. (2004), "The Economic Future of Europe", Journal of Economic Perspectives 18(4): 3-26.

Calmfors, L. and Driffil, J. (1988), "Bargaining Structure, Corporatism and Macroeconomic Performance", Economic Policy, 3(6): 14-61.

Davis, S.J. and Henrekson, M. (2004), "Tax Effects on Work Activity, Industry Mix and Shadow Economy Size: Evidence from Rich-Country Comparisons", NBER Working Paper, No10509.

De Grauwe, P. (2008), "Let's Stop Being So Gloomy About Europe”, CEPS Working Document No. 293/May 2008, Centre for European Policy Studies, Bruxelles.

Faggio, G. and Nickell, S. (2007), "Patterns of Work across the OECD", The Economic Journal, 117, F416-F440.

Freeman, R.B. (1988), "Labour Market Institutions and Economic Performance", Economic Policy, 3(6): 63-80.

Glaeser, E.L, J.A. Scheinkman, and Sacerdote, B.I. (2003), “The social multiplier”, Journal of the European Economic Association, 1(2-3): 345-353.

Groedner, A. and Knieser, T.J. (2006), "Social Interactions in Labor Supply", Journal of the European Economic Association, 4(6):1226-1248.

Nickell, S. (2004), “Employment and Wages”, CEP Discussion Paper 634, London School of Economics.

Nickell, W. (2006), The CEP-OECD Institutions Data Set (1960-2004), London School of Economics, CEP Discussion Paper No 759.

Nicoletti, G. and Scarpetta, S. (2002), "Interactions between Product and Labour Market Regulations: Do They Affect Employment? Evidence from OECD Countries", OECD, Paris.

OECD (2004), Employment Outlook (Paris: OECD).

Olovsson, C. (2009), "Why Do European Work so Little"?, International Economic Review, 50(1): 39-61.

Pekkarinen, J., M. Pohjola, and Rowthorn, B. (1992), Social corporatism: A superior economic system? Oxford: Clarendon Press.

Prescott, E. C. (2003), "Why do Americans Work so Much More than Europeans?”, Federal Reserve Bank of Minneapolis, Research Department Staff Report 321.

Rogerson, R. (2007), “Taxation and Market Work: Is Scandinavia an Outlier?", NBER Working Paper 12890. 
Rogerson, R. (2008), "Structural Transformation and the Deterioration of European Labour Market Outcomes", Journal of Political Economy, 116, 235-254.

Scheinkman, J.A. (2008). "Social Interactions", in The New Palgrave Dictionary of Economics, 2nd edition, S. Durlauf and L. Blume (eds.), Palgrave Macmillan.

Summers, L., J. Gruber and Vergara, R. (1993), "Taxation and Structure of Labor Markets: The Case of Corporatism", Quarterly Journal of Economics, 108, 385-411. 


\section{Appendix 1}

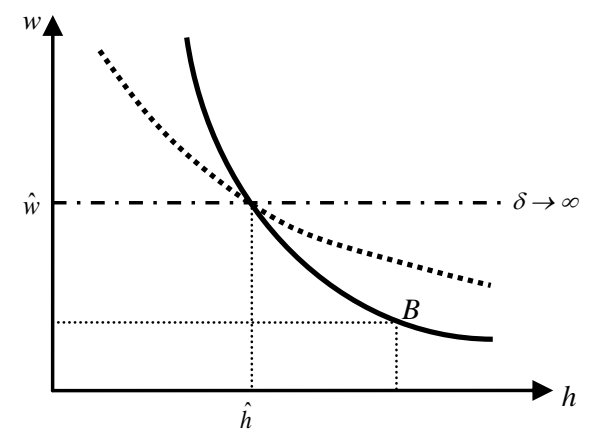

Fig. 1. Demand for work hours in general equilibrium; Solid (broken) lines correspond to small (large) $\delta$.

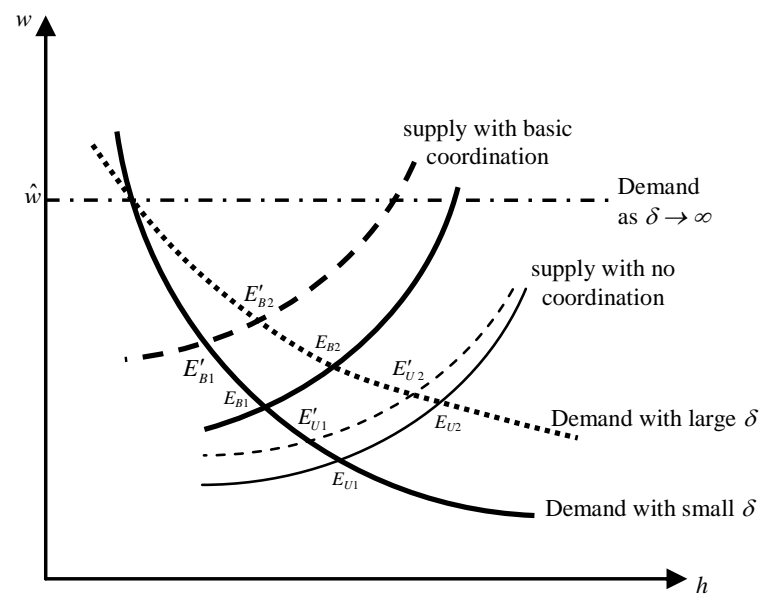

Fig. 3. General equilibrium solution with capital inflow and basic coordination; Broken supply lines correspond to a larger $\beta$

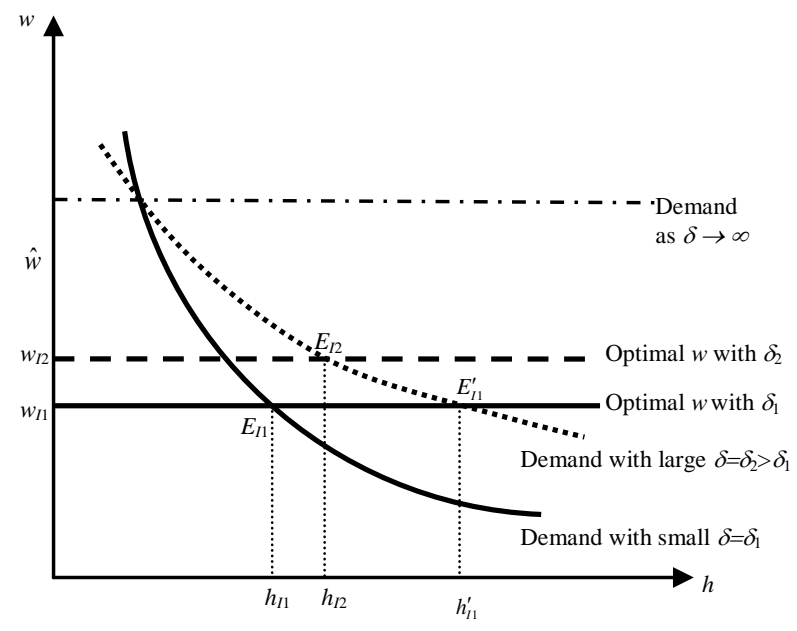

Fig. 5. General equilibrium solution with capital inflow and intermediate coordination; Role of openness for a given $\beta$

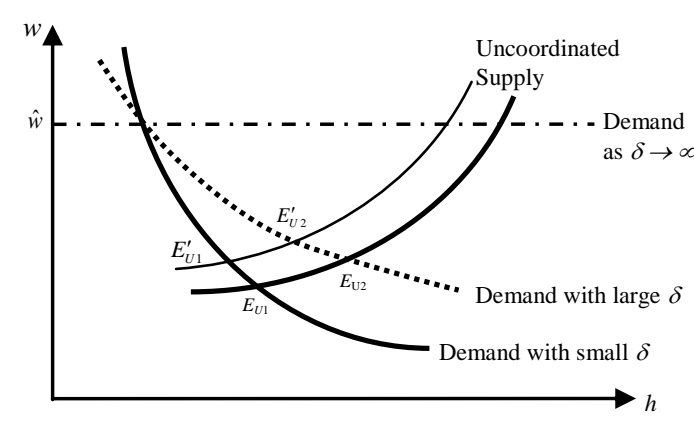

Fig. 2. General equilibrium solution with capital inflow and no coordination; The thinner uncoordinated supply corresponds to a larger $\beta$

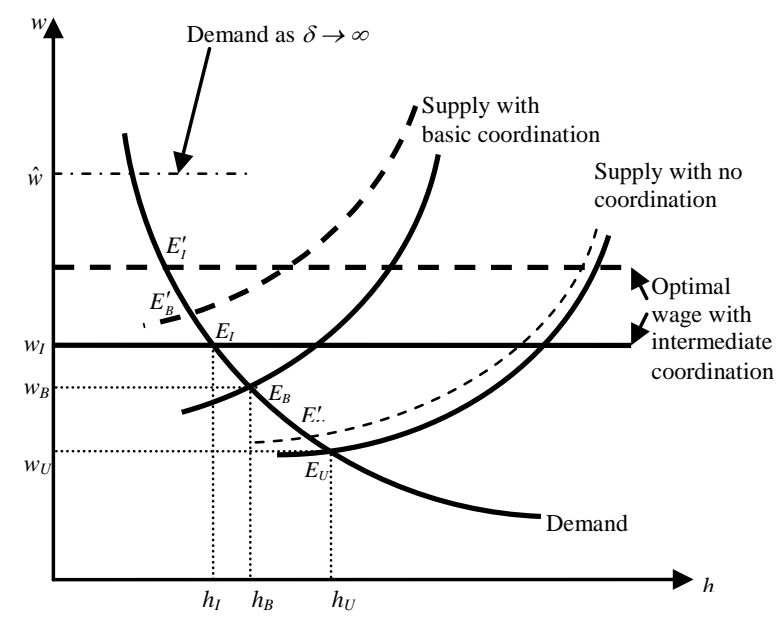

Fig. 4. General equilibrium solution with capital inflow and intermediate coordination; Role of social interaction and comparison with basic coordination and no coordination for a given $\delta$; broken lines correspond to a larger $\beta$

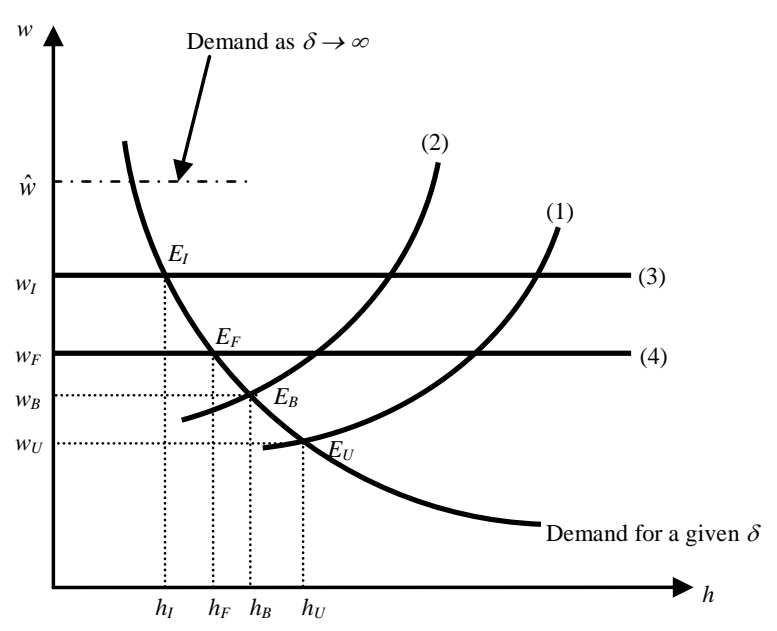

Fig. 6. General equilibrium solution with capital inflow and 'full' coordination; Role of social interaction and comparison with other cases; (1) Supply with no coordination; (2) Supply with basic coordination; (3) Supply with intermediate coordination; (4) Supply with full coordination; 


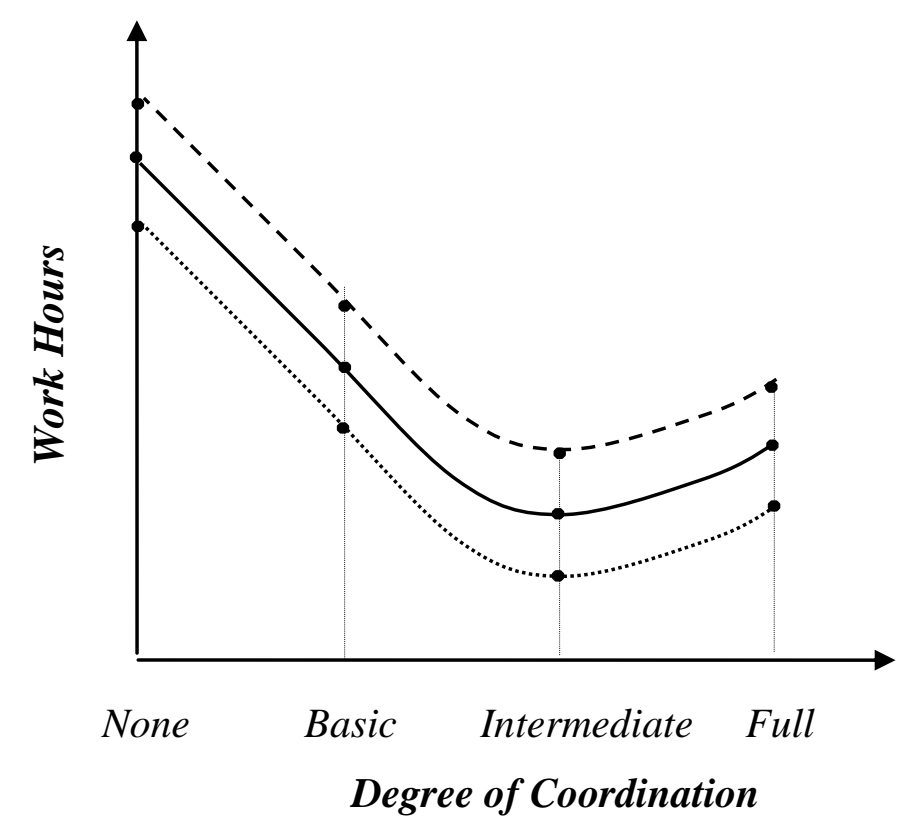

Fig. 7 Relationship between work hours and degree of coordination with capital inflow. The dashed and dotted lines show the impact of a rise in $\delta$ and $\beta$, capturing the effect of a rise in openness and the social multiplier respectively, relative to the solid line.

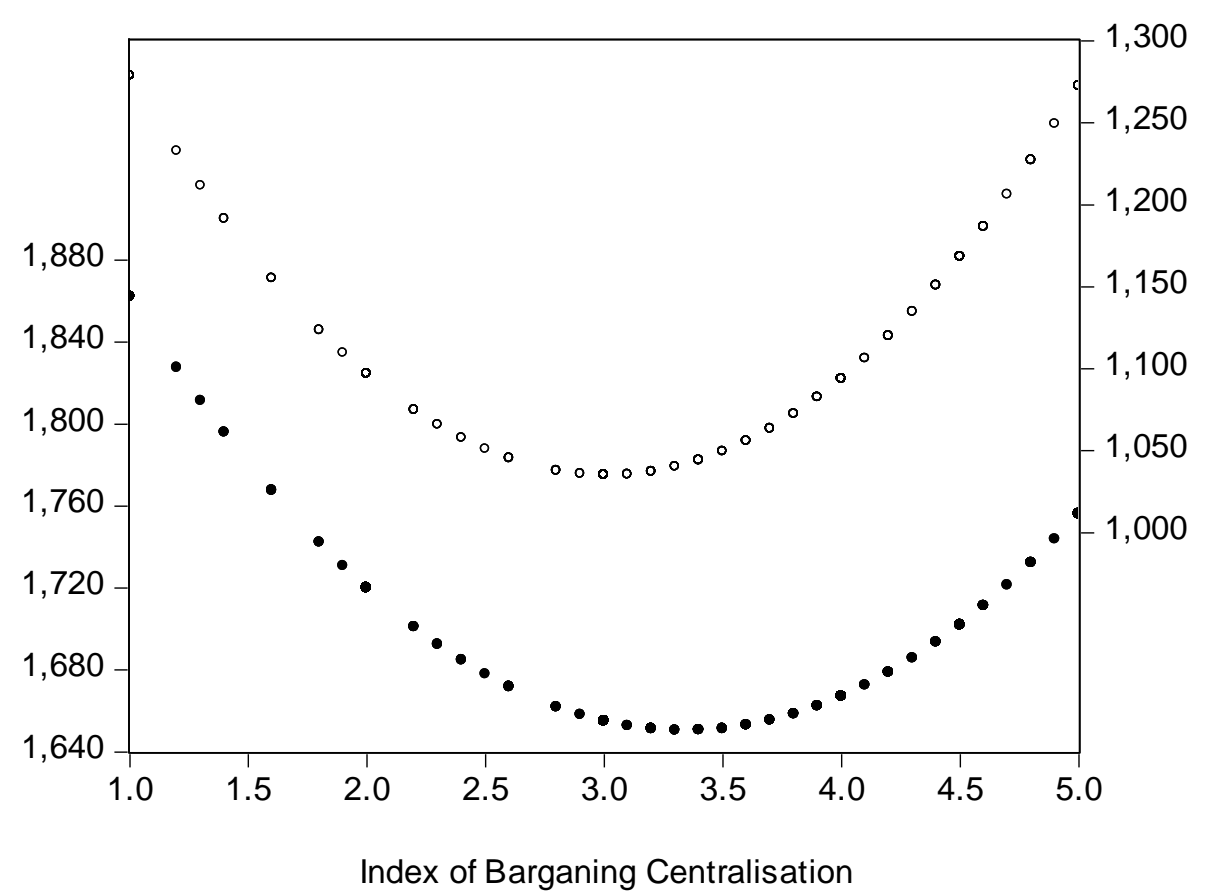

- Work Hours Per Employed Person, on Left Axis

- Work Hours Per Working Age Person, on Right Axis
Fig. 8 Relationship between work hours per employed person per year and degree of centralisation of wage bargaining process based on evidence from 18 OECD countries over the period 1970-2000. 


\section{Appendix 2}

This appendix proves the existence of a U-shaped relationship between work hours and the degree of coordination, i.e. $h_{I}<h_{F}<h_{B}$. We focus on the capital inflow case but the same approach can be used to show the result to hold also when there is capital outflow. For convenience, we replace equations (2), (4) to (7) and (10) respectively with (A1) to (A5) below which rewrite the latter equations in general form and specify the sign of their relevant partial derivatives:

$$
\begin{aligned}
& w=w(h, k) ; \quad w_{h}=-\lambda(1-\lambda) A k^{\lambda} h^{-(1+\lambda)}<0 \\
& r=r(w) ; \quad r_{w}=-\left(\frac{(1-\lambda) A}{w}\right)^{1 / \lambda}<0 \\
& u=v(c)+\ell(e) ; \quad v_{c}>0, v_{c c}<0, \ell_{e}>0, \ell_{e e}<0 \\
& k=k(r) ; \quad k_{r}=\frac{\delta \bar{k}}{r^{*}}>0 \\
& w=g(h) ; g_{h}<0
\end{aligned}
$$

The general problem is to choose $h$ to maximise $u$ in (A5), the first order condition (FOC) for which is: $v_{c} \frac{d c}{d h}+\ell_{e} \frac{d e}{d h}=0$. Since $\frac{d e}{d h}=-1$, the FOC can be written as

$$
v_{c} \frac{d c}{d h}=\ell_{e}
$$

which states the equality between marginal utilities of consumption and leisure due to a change in $h$.

With basic coordination, we impose the budget constraint in (9.1), $c=w h+r \bar{k}$, and take $w$ and $r$ as given, hence $\frac{d c}{d h}=w$ and (A6) implies

$$
v_{c} w=\ell_{e} .
$$

With intermediate coordination, we impose $c=w h+r \bar{k}$ as well as $w=w(h, k)$ in (A2) and take $k$ and $r$ as given, hence $c=w(h) \cdot h+r \bar{k}$ and $\frac{d c}{d h}=w+w_{h} h$. Therefore, (A6) implies

\footnotetext{
${ }^{19}$ Note that although equation (10) is written such that $h$ is a function of $w$, the underlying function is monotonically decreasing one and hence the inverse function in (A5) exists.
} 
$v_{c}\left(w+w_{h} h\right)=\ell_{e}$.

With full coordination, we impose $c=w h+r \bar{k}$ as well as $r=r(w)$ and $w=g(h)$ in (A4) and (A10). Thus, $c=g(h) \cdot h+r(g(h)) \cdot \bar{k}$ and $\frac{d c}{d h}=w+g_{h} h+r_{w} g_{h} \bar{k}$, and (A6) implies $v_{c}\left(w+g_{h} h+r_{w} g_{h} \bar{k}\right)=\ell_{e}$.

The right-hand-sides of (A7), (A8) and (A9) are identical. Comparing the left-handsides of these, it can be shown that (see below)

$$
w+w_{h} h<w+g_{h} h+r_{w} g_{h} \bar{k}<w,
$$

which implies:

(i) The value of $h$ which solves (A8) will have to be lower than that which solves (A7) so as to yield a relatively lower marginal utility of leisure, since $w+w_{h} h<w$, hence $h_{I}<h_{B}$

(ii) The value of $h$ which solves (A9) will have to be lower than that which solves (A7) so as to yield a relatively lower marginal utility of leisure, since $w+g_{h} h+r_{w} g_{h} \bar{k}<w$, hence $h_{F}<h_{B} ;$

(iii) The value of $h$ which solves (A8) will have to be lower than that which solves (A8) so as to yield a relatively lower marginal utility of leisure, since $w+w_{h} h<w+g_{h} h+r_{w} g_{h} \bar{k}$, hence $h_{I}<h_{F}$.

From these, $h_{I}<h_{F}<h_{B}$ follows.

To see that (A10) holds, first note that $w+w_{h} h<w$ always holds since $w_{h}<0$ does. Thus we need to establish $w_{h} h<g_{h} h+r_{w} g_{h} \bar{k}<0$ to ensure (A10). To do so, given that $g_{h}<0$ and $w_{h}<0$, we show that $w_{h} / g_{h}>1$ and that with constant returns to scale $1>1+r_{w} \bar{k} / h>0$ holds. These, together with $w+w_{h} h<w$, are sufficient for (A10) to hold.

That $w_{h} / g_{h}>1$ holds can be verified algebraically by comparing derivatives of (10) and (2). However, to retain generality here we invoke intuition to explain the reason why the partial equilibrium demand for work hours in (A1) in the $(h, w)$ space ought to be steeper than the general equilibrium locus in (A5). Consider Figure A below which sketches graphs of two partial equilibrium demands corresponding to two different levels of capital. Suppose that point $D$ is also on the general equilibrium locus. Let hours drop from $h$ to $h^{\prime}$ but keep wage intact at $w$, hence moving to point $B$. This drop in hours has two effects. First, it increases the 
marginal product of labour. Hence, if nothing else changes, at $B$ there is excess demand for hours and firms are willing to pay $w^{\prime \prime}$. But the drop in hours also reduces the marginal product of capital. This shifts the partial equilibrium demand for capital down in the $(k, r)$ space. Since the position of supply of capital is not affected, both $r$ and $k$ fall along the supply of capital as demand for capital shifts down. This fall in $k$, however, shifts the partial equilibrium demand for hours in the $(h, w)$ space down, say, to that shown by $\left(\mathrm{A} 1^{\prime}\right)$. The point on the general equilibrium locus corresponding to $h^{\prime}$ will be on (A1'). Thus, the general equilibrium locus will pass through $D$ and $D^{\prime}$ and will be flatter that any partial equilibrium demand it crosses.

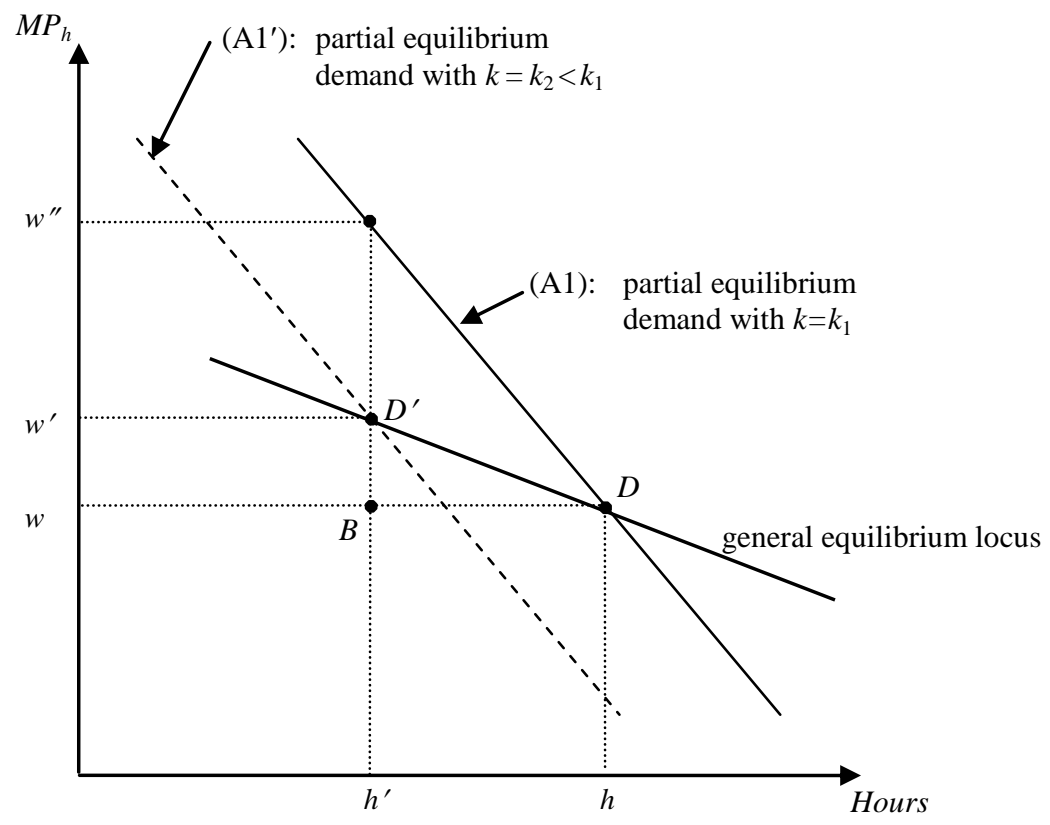

Fig. A. Partial equilibrium demand for hours and the corresponding general equilibrium locus

To show that $1>1+r_{w} \bar{k} / h>0$, first recall that $r_{w}<0$ and hence $1>1+r_{w} \bar{k} / h$ are always satisfied. To verify $1+r_{w} \bar{k} / h>0$ rewrite it as: $-r_{w}<(h / \bar{k})=(k / \bar{k})(h / k)$. With a homogenous, constant returns to scale production function, perfect competition implies that firms substitute the two factors such that the elasticity of $r$ with respect to $w, \varepsilon_{r, w}$, is a constant equal to the factor cost ratio $w h / r k=\phi$; in this case, with the Cobb-Douglas function in (1), $\varepsilon_{r, w} \equiv-\frac{r_{w}}{r / w}=\frac{w h}{r k}=(1-\lambda) / \lambda-$ see equations (2), (3) and (4). This implies $-r_{w}=h / k<h / \bar{k}$, as required since $k>\bar{k}$ with capital inflow. 
Department of Economics:

Skriftserie/Working Paper:

2009:

WP 09-1 Tomi Kyyrä, Pierpaolo Parrotta and Michael Rosholm: The Effect of Receiving Supplementary UI Benefits on Unemployment Duration ISBN 9788778824035 (print); ISBN 9788778824042 (online)

WP 09-2 Dario Pozzoli and Marco Ranzani: Old European Couples' Retirement Decisions: the Role of Love and Money ISBN 9788778824165 (print); ISBN 9788778824172 (online)

WP 09-3 Michael Gibbs, Mikel Tapia and Frederic Warzynski: Globalization, Superstars, and the Importance of Reputation: Theory \& Evidence from the Wine Industry ISBN 9788778824189 (print); ISBN 9788778824196 (online)

WP 09-4 Jan De Loecker and Frederic Warzynski: Markups and FirmLevel Export Status ISBN 9788778824202 (print); ISBN 9788778824219 (online)

WP 09-5 Tor Eriksson, Mariola Pytliková and Frédéric Warzynski: Increased Sorting and Wage Inequality in the Czech Republic: New Evidence Using Linked Employer-Employee Dataset ISBN 9788778824226 (print); ISBN 9788778824233 (online)

WP 09-6 Longhwa Chen and Tor Eriksson: Vacancy Duration, Wage Offers, and Job Requirements - Pre-Match Data Evidence ISBN 9788778824240 (print); ISBN 9788778824257 (online)

WP 09-7 Tor Eriksson, Valérie Smeets and Frédéric Warzynski: Small Open Economy Firms in International Trade: Evidence from Danish Transactions-Level Data ISBN 9788778823861 (print); ISBN 9788778823878 (online)

WP 09-8 Dario Pozzoli and Marco Ranzani: Participation and Sector Selection in Nicaragua ISBN 9788778823885 (print); ISBN 9788778823892 (online) 
WP 09-9 Rikke Ibsen, Frederic Warzynski and Niels Westergård-Nielsen: Employment Growth and International Trade: A Small Open Economy Perspective ISBN 9788778823908 (print); ISBN 9788778823915 (online)

WP 09-10 Roger Bandick and Holger Görg: Foreign acquisition, plant survival, and employment growth ISBN 9788778823922 (print); ISBN 9788778823939 (online)

WP 09-11 Pierpaolo Parrotta and Dario Pozzoli: The Effect of Learning by Hiring on Productivity

ISBN 9788778823946 (print); ISBN 9788778823953 (online)

WP 09-12 Takao Kato and Pian Shu

Peer Effects, Social Networks, and Intergroup

Competition in the Workplace

ISBN 9788778823984 (print); ISBN 9788778823991 (online)

WP 09-13 Sanne Hiller and Erdal Yalcin: Switching between Domestic Market Activity, Export and FDI

ISBN 9788778824004 (print); ISBN 9788778824028 (online)

WP 09-14 Tor Eriksson and Mariola Pytlikova: Foreign Ownership Wage Premia in Emerging Economies: Evidence from Czech Republic ISBN 9788778824035 (print); ISBN 9788778824042 (online)

WP 09-15 Astrid Würtz Rasmussen: Family Structure Changes and Children's Health, Behavior, and Educational Outcomes ISBN 9788778824059 (print); ISBN 9788778824066 (online)

WP 09-16 Tor Eriksson: How Many Danish Jobs Can (Potentially) Be Done Elsewhere?

ISBN 9788778824073 (print); ISBN 9788778824080 (online)

WP 09-17 Lorenzo Cappellari, Claudio Lucifora and Dario Pozzoli: Determinants of Grades in Maths for Students in Economics ISBN 9788778824103 (print); ISBN 9788778824110 (online)

WP 09-18 Yingqiang Zhang and Tor Eriksson: Inequality of Opportunity and Income Inequality in Nine Chinese Provinces, 1989-2006 ISBN 9788778824127 (print); ISBN 9788778824134 (online) 
WP 09-19 Ricard Gil and Frederic Warzynski: Vertical Integration, Exclusivity and Game Sales Performance in the U.S. Video Game Industry ISBN 9788778824141 (print); ISBN 9788778824165 (online)

WP 09-20 Christian Gormsen: Intransparent Markets and Intra-Industry Trade ISBN 9788778824172 (print); ISBN 9788778824189 (online)

WP 09-21 Jan Bentzen and Valdemar Smith: Wine production in Denmark Do the characteristics of the vineyards affect the chances for awards?

ISBN 9788778824196 (print); ISBN 9788778824202 (online)

WP 09-22 Astrid Würtz Rasmussen: Allocation of Parental Time and the Long-Term Effect on Children's Education ISBN 9788778824233 (print); ISBN 9788778824240 (online)

2010:

WP 10-01 Marianne Simonsen, Lars Skipper and Niels Skipper:

Price Sensitivity of Demand for Prescription Drugs: Exploiting a Regression Kink Design ISBN 9788778824257 (print); ISBN 9788778824264 (online)

WP 10-02 Olivier Gergaud, Valérie Smeets and Frédéric Warzynski: Stars War in French Gastronomy: Prestige of Restaurants and Chefs'Careers ISBN 9788778824271 (print); ISBN 9788778824288 (online)

WP 10-03 Nabanita Datta Gupta, Mette Deding and Mette Lausten: Medium-term consequences of low birth weight on health and behavioral deficits - is there a catch-up effect? ISBN 9788778824301 (print); ISBN 9788778824318 (online)

WP 10-04 Jørgen Drud Hansen, Hassan Molana, Catia Montagna and Jørgen Ulff-Møller Nielsen: Work Hours, Social Value of Leisure and Globalisation ISBN 9788778824332 (print); ISBN 9788778824349 (online) 